\title{
Spelling Proficiency of Novel Phonemes in Arabic among Native Hebrew Academic Students
}

\author{
By Alon Fragman*
}

\begin{abstract}
This study examined spelling proficiency in Arabic among native Hebrew speaking students $(n=50)$ learning the written form of Arabic as a foreign language (AFL) in the Middle Eastern Studies department at one of the largest Universities in south Israel. Specifically, this study focused on ten novel phonemes (guttural, velar-uvular, dental, and emphatic). Three tasks were performed through the computer: a visual task, an auditory task and an audiovisual task. The results support previous studies which found that native Hebrew speakers learning AFL cope with extra linguistic burden, due to the fact that several Arabic phonemes visually resemble other Arabic graphemes while simultaneously corresponding with an Arabic phoneme that is similar to a familiar phoneme from the Hebrew phonemic inventory. The results also indicated that the students had difficulties representing novel phonemes which do not exist in their mother tongue, especially emphatic and dental phonemes. In addition, lower scores were achieved in the auditory task vs. the visual task and the audio-visual task. The students performed significantly better on the auditory task after two years of AFL learning, yet the scores still remained lower than the scores for the other tasks. This may be explained by the AFL curriculum and instruction, which mainly focuses on the development of reading and writing skills, while at the same time neglecting aural-oral skills in Arabic teaching. Thus, it is highly recommended to use aural-oral skills alongside the practice of other aspects of the language in order to establish successful and meaningful learning of Arabic.
\end{abstract}

Arabic is the second official language of Israel, after Hebrew. It is being learned as a second foreign language, after English, in the Educational system in Hebrew schools from seventh to tenth grades. Arabic language, literature and culture are also studied in most Israeli Universities and in some colleges. Recent studies of novel phoneme representations among native Hebrew speaking pupils learning Arabic as a foreign language (AFL) in junior high school in Israel, indicated that native Hebrew speaking pupils had very low proficiency in grapheme-phoneme representations of novel phonemes even after four years of exposure and practice (Fragman \& Russak, 2010; Russak \& Fragman,

*Arabic Studies Coordinator, Middle Eastern Studies Department, Ben Gurion University, Israel. 
forthcoming). These results were surprising; one would have expected that learning AFL would not be so difficult for native Hebrew speakers, since both languages are Semitic and share linguistic commonalities (Shimron, 2003). The researchers suggested that the low scores could be explained by the fact that native Hebrew speakers learning AFL have to cope with orthographic as well as phonological complexities simultaneously (Russak \& Fragman, forthcoming).

In the Middle Eastern Studies department at one of the largest Universities in the south of Israel, where the present study was conducted, students learn the written form of Arabic during all three years of their B.A. studies. According to the Arabic curriculum of the first year in the Middle Eastern Studies department, all students learn the basics of AFL for six hours a week. The program emphasizes learning general and daily vocabulary, exercising grammatical and syntactic issues, as well as reading short articles from the newspapers' first page. In the second year, however, the students are allowed to choose between a standard track of AFL learning, in which they learn two weekly hours of AFL for additional two semesters, and an intensive track of Arabic, in which they learn Arabic thoroughly for eight hours per week in each semester. In both tracks, the students study listening comprehension through communications media, in addition to reading newspapers and Arabic literature, however to different degrees.

\section{Linguistic Similarities and Differences between Arabic and Hebrew}

Arabic and Hebrew are both alphabetic Semitic languages, read and written from right to left. Both languages have different printed and handwriting systems of the script. All verbs and most nouns are written primarily as three to four letter consonantal roots that are differently affixed and vowelled to form the words of the lexicon (Berman, 1978; Ravid \& Schiff, 2006). Patterns, regularly formed by a combination of vowels and other extra consonants, produce nouns with number and gender and define the final word-form (Shimron, 2003). In their scripts, vowels are represented within consonantal graphemes by diacritic marks.

In addition to the shared linguistic similarities shown above, there are several phenomena that both languages share, yet to different degrees (Fragman \& Russak, 2010). For example, while 22 of the 28 letters in Arabic are written connected to the following letters, and only six letters are written with no connection to their following letter, in the Hebrew script no letters are written connected to the following letter.

Dots are another linguistic characteristic that both languages share to different degrees. Dots are acceptable diacritic marks in both languages, however, while in Hebrew there are only three instances where dots mark allophones (p-f, k-x, b-v), in Arabic, dots are an integral and obligatory part of 15 letters. These letters in Arabic share a similar or even identical basic structure and are distinguished only on the basis of the existence, location and number of dots.

Another phenomenon that both Hebrew and Arabic orthographies share, is letters that are represented by multiple shapes, written differently according to their placement in the word. However, while in Hebrew there are only five letters 
that change shape when they are in word final position, in Arabic this phenomenon is much more extensive; 22 letters have remarkable changes in letter shape, according to their placement in the word (Azzam, 1984).

Cross-linguistic research has pointed out the cognitive burden that is created by additional orthographic information in Arabic, as compared with other orthographies, such as the Hebrew orthography (Azzam, 1993; Eviatar, Ibrahim, \& Ganayim, 2004; Ibrahim, Eviatar \& Aharon-Perez 2002). Other studies have indicated that the diglossic nature of Arabic (the use of two varieties of the language - the spoken and the written form - within the Arabic speakers' community) affects literacy acquisition processes from phoneme awareness tasks to word reading and spelling (Saiegh-Haddad, 2003; Abu-Rabia \& Taha, 2004).

Abu-Rabia \& Siegel's study (1995) found that trilingual native Arabic speaking $8^{\text {th }}$ graders made various spelling errors, including confusion between short vowels and long vowels; errors in writing words that combined two similar sounds /s/ and /ş/ or /t/ and /ţ/; errors in writing words as a result of homophones; and errors in writing four syllable words. Further studies conducted by Abu-Rabia \& Taha $(2004,2006)$, who examined the types of spelling errors made by native Arabic-speaking pupils in grades 1 through 9, found that the most prominent types of errors across grade levels were phonetic, representing $50 \%$ of all errors.

With regard to grapheme-phoneme correspondences in AFL among native Hebrew speakers, it has been argued by Russak \& Fragman (forthcoming) that there is an additional cognitive burden for native Hebrew learners in the establishment of accurate grapho-phonemic representations of the written form of AFL, since there are some letters in Arabic that are orthographically similar to other letters, while simultaneously being phonetically similar to other phonemes that exist in both Arabic and Hebrew (Russak \& Fragman, forthcoming). The researchers concluded that the phonetic proximity of novel phonemes in AFL and familiar ones in Hebrew (L1) could be a deterrent in the establishment of grapheme-phoneme representations for the native Hebrew learners of AFL. This phenomenon was also found problematic in studies among native Arabic speakers (Saiegh-Haddad, 2003, 2004, 2005, 2007), while other studies pointed out the effect of orthographic complexity on the acquisition of the written form of Arabic by native Arabic speakers (Abu-Rabia \& Taha 2004, 2006; Eviatar, Z., Ibrahim, R., \& Ganayim, D., 2004) and by native English speakers (Khaldieh, 1996).

This study aims to explore the spelling developmental trajectory for novel phonemes in AFL among native Hebrew academic students at the end of the $1^{\text {st }}$ and the $2^{\text {nd }}$ year of AFL exposure, in order to examine the changes in their linguistic knowledge over time.

\section{Research Aim and Research Questions}

This study aimed to examine the developmental trajectory for ten novel phonemes in Arabic (guttural: among native Hebrew speaking students after the first and the second 
years of learning of the written form of the language at the university. Therefore, the research question was:

What is the developmental trajectory for guttural $(\tau)$ ), velar-uvular $(\ddot{\varepsilon})$ ), dental (ظ) (ظ, ط, ض, ص) novel phonemes in AFL among native Hebrew speaking students after the first and the second years of learning the written form of Arabic at the university?

\section{Method}

\section{Participants}

Participants in this study included 50 native Hebrew speaking students learning Arabic as a foreign language in the Middle Eastern Studies department at one of the largest universities in south Israel (26 female, 24 male). Out of fifty students, sixteen were first year students, while 34 were second year students, out of which seventeen were studying Arabic in a standard course (two hours a week) and seventeen were learning Arabic in an intensive course (eight hours a week) of the second year. Twelve students had prior knowledge of Arabic, for example from junior high school studies. Students with learning disabilities of any kind were excluded from the sample.

\section{Task Construction}

The present study included three experimental tasks which were created for the study: visual task, auditory task and audio-visual task. The tasks were based on similar tasks that were used in the previous studies of spelling error analysis of AFL among native Hebrew speaking junior high school pupils (Fragman \& Russak, 2010), however all tasks in this study were performed through the computer. Each task was randomly given to the students. For each task, there were forty words randomly presented to the students. After performing ten words in a certain task, the task was automatically replaced. All words used in the experimental tasks were pseudo words. By doing so, it was expected to minimize the students' use of whole word memorization for spelling (Sun-Alperin, 2007). Pseudo words were chosen and created from a real word corpus which the students in Middle Eastern Studies department were exposed to during the $1^{\text {st }}$ year of AFL, by changing one phoneme-grapheme pattern in a real word, for example: /murun/ instead of /mudun/ (cities). Each pseudo word included one novel phoneme, at the beginning, in the middle or at the end of the word. Pseudo words were nouns only, comprised of two or three syllables. They were presented to the students without an additional vowel in the last letter of the noun $\left(I^{\prime} r \bar{a} b\right)$, since the students are used to exercise the written form of Arabic without it most of the time. By pressing a button, the students could ask the computer to show or to hear the word presented to them as many times as they wanted. Then, they were asked to type the word from their memory. The computer checked spelling accuracy for the novel phonemes examined in this study only. 


\section{Procedure}

This study was conducted in the Middle Eastern Studies department laboratory with the assistance of the computer department. Data was collected towards the end of the academic year, in May-June 2011. The students performed the tasks anonymously by using their ID number and personal password. Each student performed the given tasks for one academic hour. Data was collected by the computer department which handed it to the researcher only after this phase was completed.

\section{Results}

This study was set to explore the spelling developmental trajectory for ten novel phonemes in Arabic (guttural: emphatic: ظ (ظ, ط, ض, ص among native Hebrew speaking students after the first and the second years of learning of the written form of the language at the university.

A multilevel logistic regression analysis was performed in order to generalize the nature and the structure of our data. The hierarchical regressions analyses found seven main effects (see table 1):

(1) Two main effects for tasks - A main effect for correct spelling in the visual task as opposed to the auditory task $(\mathrm{ME}=19.80)$, and a main effect for correct spelling in the audio-visual task as opposed to the auditory task $(\mathrm{ME}=21.62)$. These effects reflect the difference between the probability of 74.37 $\%$ for success in the auditory task versus the probability of $94.17 \%$ for success in the visual task and $95.99 \%$ for success in the audio-visual task. (2) Three main effects for novel phonemes - A main effect for correct spelling of velar-uvular phonemes $(\mathrm{ME}=-11.93)$, of dental phonemes $(\mathrm{ME}=-30.68)$ and of emphatic phonemes $(\mathrm{ME}=-29.43)$ as opposed to guttural phonemes. These main effects reflect the probability of $62.43 \%$ for success on velar-uvular phonemes, the probability of $43.69 \%$ for success on dental phonemes, and the probability of $44.94 \%$ for success on emphatic phonemes as opposed to $74.37 \%$ for success on guttural phonemes. (3) A main effect for repetition of words asked by the students $(\mathrm{ME}=-.01)$. The hierarchical regressions analyses show that the average number of times which students asked for repetition of words was $2.74(\mathrm{SD}=1.93)$. The results indicate that the more students asked to view or to hear a word presented in the study, their chances for a correct answer decreased by $1 \%$. (4) On the participant's level, there was a main effect for AFL time of exposure - The contribution of time of exposure and practice increased in the end of the second year in the AFL intensive group only as opposed to the end of the first year of AFL (ME=8.52). 
Table 1. Regression Analysis: Main Effects for Tasks, Novel Phonemes, Time of Exposure, and Repetition of Words*

\begin{tabular}{|c|c|c|c|c|c|}
\hline Variable & Coefficient & $S E$ & $d f$ & Odds Ratio & $P$ \\
\hline \multicolumn{6}{|l|}{ Tasks } \\
\hline Visual vs. auditory task & 1.72 & .19 & 3594 & 5.57 & $<.001$ \\
\hline Audio-visual vs. auditory task & 2.11 & .16 & 3594 & 8.25 & $<.001$ \\
\hline \multicolumn{6}{|l|}{ Novel phonemes } \\
\hline Emphatic vs. guttural phonemes & -1.27 & .21 & 3594 & .28 & $<.001$ \\
\hline Velar-uvular vs. guttural phonemes & -.56 & .21 & 3594 & .57 & .010 \\
\hline Dental vs. guttural phonemes & -1.32 & .21 & 3594 & .27 & $<.001$ \\
\hline Repetition of words & -.06 & .03 & 3594 & .94 & .033 \\
\hline \multicolumn{6}{|l|}{ Time of exposure } \\
\hline Second year standard course vs. 1st year & .39 & .31 & 46 & 1.48 & .211 \\
\hline Second year intensive course vs. 1st year & .51 & .25 & 46 & 1.67 & .050 \\
\hline Word length: 3 vs. 2 syllables & .17 & .11 & 3594 & 1.18 & .126 \\
\hline Prior knowledge in Arabic & .26 & .34 & 46 & 1.29 & .452 \\
\hline \multirow[t]{2}{*}{ Random Effect } & Variance & $S D$ & $\chi^{2}$ & $D f$ & $P$ \\
\hline & .68 & .83 & 269.39 & 46 & $<.001$ \\
\hline
\end{tabular}

* Results with robust standard errors reported

The hierarchical regressions analyses found no effect for prior knowledge of Arabic. Also, word length (number of syllables) was not found as a factor that contributed to correct spelling.

However, there were six interactions for tasks according to the hierarchical regressions analyses (see table 2):

Table 2. Regression Analysis: Interactions for Tasks*

$\begin{array}{lllll}\text { Variable } & \text { Coefficient } & S E & d f & \begin{array}{l}\text { Odds } \\ \text { Ratio }\end{array}\end{array} \quad P$

\section{Tasks over time (2nd year vs. 1 st year of exposure)}

\begin{tabular}{lccccc} 
Visual vs. auditory task - intensive group & -1.08 & .44 & 3582 & .34 & $.015^{*}$ \\
$\begin{array}{l}\text { Audio-visual vs. auditory task - standard } \\
\text { group }\end{array}$ & -.79 & .31 & 3582 & .45 & $.010^{*}$ \\
$\begin{array}{l}\text { Audio-visual vs. auditory task - intensive } \\
\text { group }\end{array}$ & .23 & .37 & 3582 & 1.26 & .539 \\
\hline
\end{tabular}




\section{Novel phonemes and tasks}

Emphatic phonemes in visual task

$\begin{array}{lllll}1.56 & .40 & 3582 & 4.78 & .001 * \\ 1.38 & .45 & 3582 & 3.98 & .002 * \\ 1.08 & .41 & 3582 & 2.96 & .009 * \\ .70 & .46 & 3582 & 2.01 & .129 \\ .67 & .39 & 3582 & 1.95 & .090 \\ .71 & .44 & 3582 & 2.03 & .107\end{array}$

Emphatic phonemes in audio-visual task

Dental phonemes in visual task

Dental phonemes in audio-visual task

Velar-uvular phonemes in visual task

Velar-uvular phonemes in audio-visual task

Number of syllables and tasks

Three vs. two syllables in visual task .54

$.21 \quad 3582$

$1.71 \quad .010 *$

Three vs. two syllables in audio-visual task

$\begin{array}{lllll}.39 & .23 & 3582 & 1.48 & .090\end{array}$

\begin{tabular}{cccccc}
\hline Random Effect & Variance & $S D$ & $\chi 2$ & $D f$ & $P$ \\
\hline & .79 & .89 & 295.77 & 46 & $<.001$
\end{tabular}

* Results with robust standard errors reported

(1) Two interactions for tasks and time of AFL exposure - An interaction between visual task as opposed to auditory task for the intensive group in the end of the second year vs. the end of the first year of AFL learning $\gamma_{21}=-1.08, t(3582)=-2.44, \mathrm{p}<.05$ (see figure 1$)$.

Figure 1. An Interaction for Visual vs. Auditory Task in the Second Year As Opposed To The First Year Of Exposure And Practice For AFL Intensive Group

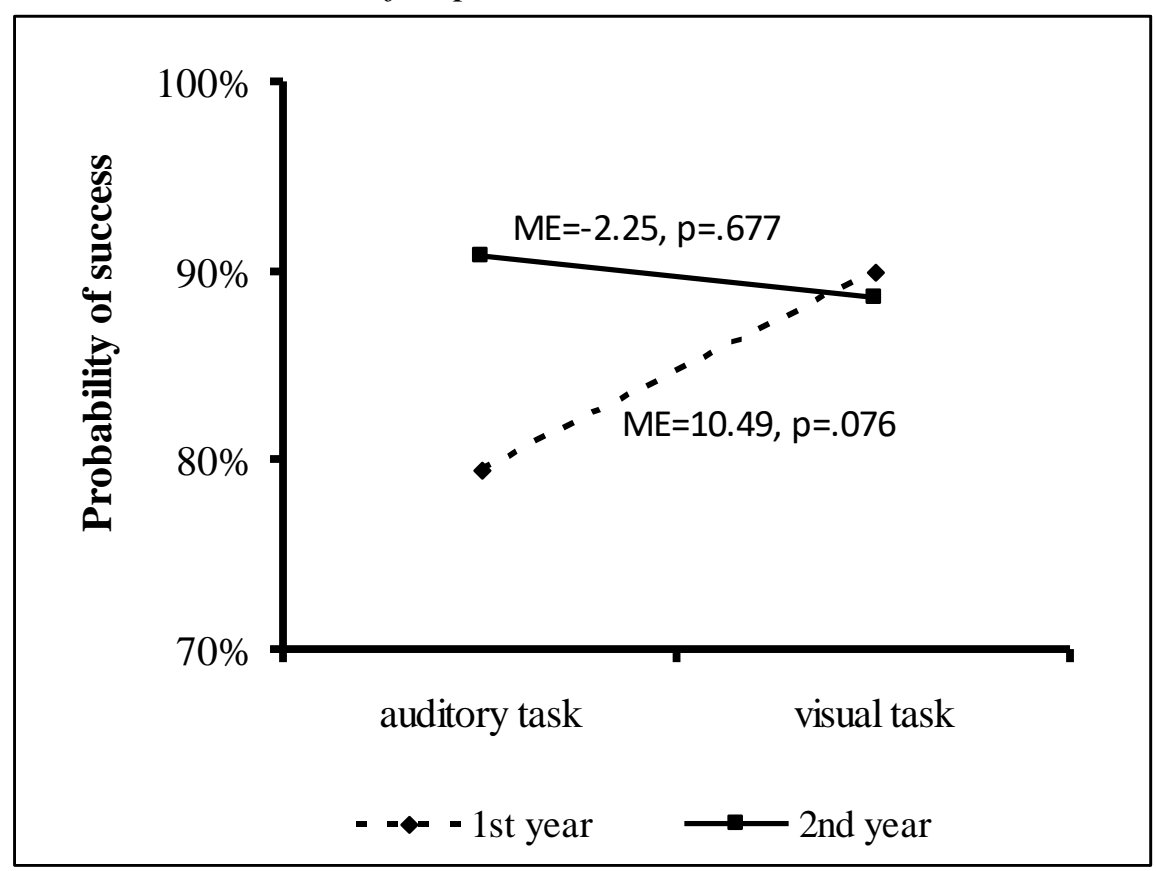


(2) Also, there was an interaction between the audio-visual task as opposed to the auditory task for the standard AFL group in the end of the second year vs. the end of the first year of exposure and practice $\gamma_{21}=-.79, t(3582)=-2.55, \mathrm{p}<.05($ see figure 2$)$.

Figure 2. An Interaction for Audio-Visual vs. Auditory Task in the Second Year as Opposed to the First Year of Exposure and Practice for AFL Standard Group

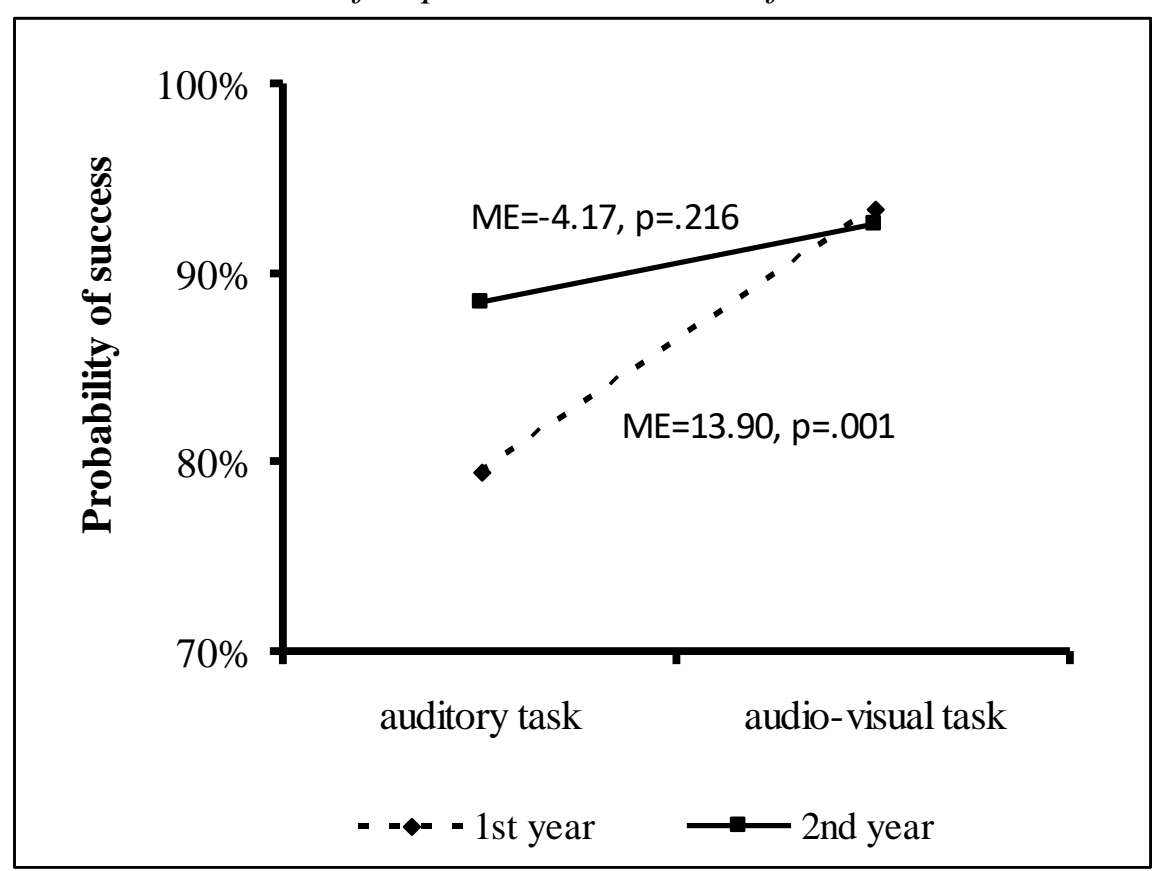

According to these interactions, while the probability to spell correctly for students learning in the intensive group in the visual task and for students in the standard group in the audio-visual task remains approximately $90 \%$ from the end of the first year to the end of the second year of AFL learning, the probability for a correct spelling in the auditory task significantly improves over time from $79.43 \%$ to approximately $90 \%$.

(2) Three interactions for novel phonemes and tasks - An interaction between the visual task as opposed to the auditory task for emphatic phonemes $\gamma_{2 l}=1.56$, $t(3582)=3.9, \mathrm{p}<.001$ and for dental phonemes vs. guttural phonemes $\gamma_{2 l}=1.08$, $t(3582)=2.63, \mathrm{p}<.05$, and an interaction for the audio-visual task as opposed to the auditory task for emphatic phonemes vs. guttural phonemes as well, $\gamma_{21}=1.38$, $t(3582)=3.06, \mathrm{p}<.05$. According to these interactions, the probability for a correct spelling of emphatic phonemes is $84.28 \%$ in the visual task, and $87.5 \%$ in the audio-visual task, and the probability for a correct spelling of dental phonemes in the visual task is $81.06 \%$. The probability to spell guttural phonemes correctly is significantly higher in all tasks as opposed to other novel phonemes. Spelling guttural phonemes correctly is also higher in tasks that include visual stimuli, the visual task $(89.92 \%)$ and the audio-visual task $(93.33 \%)$ as opposed to the auditory task $(79.43 \%)$. 
(3) An interaction between the visual task as opposed to the auditory task for word length (number of syllables): two vs. three syllables, $\gamma_{21}=.54, t(3582)=$ $2.57, \mathrm{p}<.05$. According to this interaction, for words with two or three syllables the probability for correct spelling ranges between $89.92-93.20 \%$ in the visual task, however it is much lower in the auditory task, and ranges between 77.66$79.43 \%$.

\section{Discussion}

The main purpose of this study was to explore the development of spelling proficiency in AFL among native Hebrew speaking students after the first and the second years of learning the written form of Arabic at the university level in the Middle Eastern Studies department. In this study, we focused on the developmental trajectory for ten novel phonemes: guttural $(\varepsilon, \tau)$, velar-uvular $(\dot{\varepsilon}$ ق), dental (ث), and emphatic (ظ, ط, ض, ص).

The results indicate that the students' spelling proficiency was much higher in the tasks which included visual stimuli (visual and audio-visual tasks), as opposed to the auditory task, already from the end of the first AFL learning. Yet, spelling proficiency in the auditory task improved over time. The low scores in the auditory task in the end of the first year of Arabic learning may be attributed to the type of AFL instruction, which mainly focuses on aspects of the written form of Arabic and on the development of reading and writing skills, according to the AFL curriculum, thereby neglecting aural-oral skills, mainly in the first stages of AFL learning. Thus, we can conclude that the exposure to AFL in the first year of its learning was mainly visual, and this, in return, affected the students' spelling accuracy in the visual and audio-visual tasks. The improvement in the students' scores in the auditory task in the end of the second year of AFL learning can be attributed to the increasing exposure to oral aspects of the language and to the development of the listening skill during the second year of AFL learning, which affected the students' scores in the auditory task and improved their spelling accuracy. In previous findings of AFL among native Hebrew learners, Russak \& Fragman (forthcoming) found an improvement in the orthographic knowledge among native Hebrew tenth grade adolescents, after four years of AFL exposure and practice. However, they also found a decrease in the phonological knowledge over time. They attributed these findings to the instructional emphasis on reading and writing skills and lack of exposure to the sounds of Arabic in Hebrew schools.

In the current study, the AFL curriculum in the Middle Eastern Studies department at the university also emphasizes reading and writing skills in the first year of Arabic learning. According to the AFL curriculum, the students are exposed to the oral language mainly during their second year of AFL learning. Thus, the improvement in spelling accuracy in the auditory task in the end of the second year of AFL learning only can be attributed to the increased exposure to oral elements of the language in the second year. Additional support for this explanation can be found in a study by Allaith \& Yoshi (2011), who examined spelling performance of English consonants among fourth, sixth, eighth and tenth 
native Arabic speakers, and found that there was no difference between the Arabic participants in phoneme pair errors across the grade level in most of the phonemes targeted. They attributed little or no improvement in the spelling of novel phoneme pairs over time among elementary, junior high school and high school students to the learning setting and language instruction.

As opposed to these findings, Wang \& Geva (2003) reported a significant improvement in the spelling of novel phonemes among native Cantonese first grade pupils in a total immersion ESL program in Canada by the end of the second grade. Moreover, they reported similar levels of accuracy as their native English speakers' peers. They concluded that the language setting facilitated the development of accurate spelling in the target language. Therefore, it can be concluded that the instructional language setting is an essential factor that affects the students' proficiency in the target language. While little emphasis on auraloral skills in the Education system at Hebrew schools produced low scores in the auditory discrimination task and in the dictation task in the Russak \& Fragman study (forthcoming), it was shown in this study, as well as in Wang \& Geva study (2003), that supportive language setting and intensive exposure to the target language facilitate the development of spelling accuracy. Focusing on visual cues in order to remember the presented words in the visual task, as reported by some of the students in the current study, implies that students compensate for the lack of phonological knowledge with orthographic knowledge in the first stages of AFL learning. These results raise once again the dilemma dealt in Allaith \& Joshi's study (2011) regarding the correlation between linguistic proficiency, instruction, and error distribution. From the studies conducted by Fragman \& Russak (2010) and Russak \& Fragman (forthcoming), it seems that the instruction of AFL in the Hebrew sector plays a significant role in the process of AFL learning. While continuous learning of Arabic in Hebrew junior high schools and high schools achieved very low scores for spelling novel phonemes by eighth, ninth and tenth graders, and decrease in scores for auditory discrimination task after four years of AFL learning, the improvement in spelling accuracy in the auditory task in the second year by the students learning in the intensive track of AFL may be attributed to the targeted instruction to aural-oral skills, which was lacking in the first year, and which is also lacking in junior high schools and high schools in the Hebrew sector in Israel.

Results of this study regarding spelling proficiency for novel phonemes also show significantly higher scores for guttural phonemes as opposed to emphatic and dental phonemes in the auditory task. These results replicate the findings from a previous study of Russak \& Fragman (forthcoming), which found that native Hebrew speakers learning AFL achieved higher scores for guttural phonemes due to the fact that they existed in ancient Hebrew and still exist in the modern Hebrew landscape to some degree, and achieved low scores for emphatic phonemes due to the fact that these phonemes do not exist in modern Hebrew. Some of these phonemes, such as $/ \underline{\mathrm{s}} /$ and $/ \mathrm{d} /$, are also similar to other Hebrew phonemes (/s/ and /d/). Russak \& Fragman (forthcoming) suggested that native Hebrew speakers learning AFL find difficulty with the distinction between these phonemes, and that this similarity may hinder the learning process for them. In 
addition, native Hebrew speaking students who participated in this study also had difficulty with representing dental phonemes. A possible explanation for this can be attributed to the fact that not only are dental phonemes novel to the native Hebrew speaking AFL learner, but they also represent articulation disorders among native Hebrew speakers (Rom, Segal \& Tzur, 2003), such as the phoneme /s/ when pronounced ض among elementary school native Hebrew speaking children. The phoneme $\dot{\forall}$ does not exist in the Hebrew inventory, however many kindergarten children pronounce it instead of the phoneme /s/. Yet, it is expected that they will be able to pronounce the phoneme /s/ around the age of six, at the beginning of the first grade in the elementary school. Therefore, native Hebrew speakers who are expected to avoid using them in their mother tongue may also have difficulties with representing them phonologically in the target language, since they represent "childish" language.

This study also found that cases in which an Arabic phoneme visually resembles another Arabic grapheme while simultaneously corresponding with an Arabic phoneme that is similar to a familiar phoneme from the Hebrew phonemic inventory, such as the emphatic phonemes, were challenging for the native Hebrew learners even after two years of intensive AFL practice and exposure, for example confusing between ص ص ص which visually resemble each other (they only differ by one dot), however each of them sounds like another phoneme in Arabic (ص sounds similar to /s/, and ض sounds similar to /d/) which also exists in Hebrew. However, the fact that native Hebrew learners had also difficulties with other phonemes, such as dental phonemes (that are not similar to a familiar phoneme from the Hebrew phonemic inventory), indicates that the linguistic complexity is not the only source of difficulty for the native Hebrew learner, and that other factors, such as emotional and cultural factors, may be involved as well.

In sum, it seems that native Hebrew speakers learning AFL do cope with an extra linguistic burden, due to the fact that several Arabic phonemes visually resemble other Arabic graphemes while simultaneously corresponding with an Arabic phoneme that is similar to a familiar phoneme from the Hebrew phonemic inventory. However, the results of this study also support the possibility that good instruction that provides the learners with additional intensive exposure to Arabic, using aural-oral skills alongside the practice of other aspects of the language, provides the learners with significant higher spelling proficiency. This, in return, is essential for establishing meaningful learning of Arabic.

\section{References}

Abu-Rabia, S, \& Siegel, L.S. (1995). 'Different orthographies, different context effects: The effects of Arabic sentence context on skilled and poor readers.' Reading Psychology 16: 1 - 19.

Abu Rabia, S. \& Taha, H. (2004). 'Reading and spelling error of native Arabic dyslexic readers.' Reading and Writinl, 17, $651-689$.

Abu Rabia, S. \& Taha, H. (2006). 'Phonological errors predominate in Arabic spelling across grades 1 - 9.' Journal of Psycholinguistic Research, 35(2), 167 - 188. 
Allaith, Z.A. \& Joshi, R.M. (2011). 'Spelling performance of English consonants among students whose first language is Arabic.' Reading and Writing, 24(9), 1089-1110.

Azzam, R. (1984). 'Orthography and reading of the Arabic language.' In: J. Aaron \& R.M. Joshi (eds.), Reading and writing disorders in different orthographic systems. Kluwer Academic, 1-29.

Azzam, R, (1993). 'The nature of Arabic reading and spelling errors of young children.' Reading and Writing 5: 355-385.

Berman, R.A. (1978). Modern Hebrew Structure. Tel Aviv: Israel: University Publishing.

Eviatar, Z., Ibrahim, R. \& Ganayim, D. (2004). 'Orthography and the Hemispheres: Visual and Linguistic Aspects.' Neuropsychology 18, 174-184.

Ferguson, Charles A. (1959).'Diglossia.' Word 15: 325-340.

Fragman, A. \& Russak, S.(2010). 'A qualitative analysis of spelling errors in Arabic as a foreign language among native Hebrew speaking students.' Arabele2009: Teaching and Learning the Arabic Language: 103-114.

Ibrahim, R., Eviatar, Z. \& Aharon Peretz, J. (2002). 'The characteristics of the Arabic orthography slow its cognitive processing.' Neuropsychology 16(3): 322-326.

Khaldieh, S. (1996). 'Word recognition of Arabic as a foreign language by American learners: The role of phonology and script.' Al-'Arabiyya 29: 129-152.

Ravid, D. \& R. Schiff. (2006). 'Roots and patterns in Hebrew language development: evidence from written morphological analogies.' Reading and Writing 19: 789-818.

Rom, A., Segal, M. \& Tzur, B. (2003). A child: what does he say? language development among children. Tel Aviv: Mofet Institution (Hebrew).

Russak, S. \& Fragman, A. (forthcoming). 'The development of grapho-phonemic representation among native Hebrew speakers learning Arabic as a foreign language.' In: Saiegh-Haddad, E. \& Joshi, M. (eds.). Handbook of Arabic Literacy. Springer. Manuscript submitted for publication.

Saiegh-Haddad, E. (2003). 'Linguistic distance and initial reading acquisition: the case of Arabic diglossia.' Applied Psycholinguistics 24: 431-451.

Saiegh-Haddad, E. (2004). 'The impact of phonemic and lexical distance on the phonological analysis of words and pseudowords in a diglossic context.' Applied Psycholinguistics 25: 495-512.

Saiegh-Haddad, E. (2005). 'Correlates of reading fluency in Arabic: diglossic and orthographic factors.' Reading and Writing 18: 559-582.

Saiegh-Haddad, E. (2007). 'Linguistic constraints on children's ability phonemes in Arabic.' Applied Psycholinguistics 28(4): 607-626.

Shimron, J. (2003). 'Semitic languages: Are they really root-based?' In: Joseph Shimron (ed.). Language processing and acquisition in languages of Semitic, root-based, morphology, 1-28. Amsterdam: Benjamins.

Sun-Alperin, M.K. (2007). 'Cross-language transfer of phonological and orthographic processing skills in Spanish speaking children learning to read and spell in English.' Doctoral dissertation, University of Maryland.

Wang, M. \& Geva, E. (2003). 'Spelling acquisition of novel English phonemes in Chinese children.' Reading and Writing 16(4): 325-348. 